\title{
The impact of physical health on the postponement of retirement
}

\author{
Michael Boissonneault and Joop de Beer*
}

\begin{abstract}
To mitigate the effects of population ageing, measures aimed at encouraging people to work longer are being implemented in many countries. However, older people are usually in poorer physical health, and poorer physical health is associated with premature labour force withdrawal. We investigate whether the age-related decline in physical health represents a hurdle to higher labour force participation levels at older ages by proposing a simulation in which the age profile of physical health stays constant over time, while all other factors that predict labour force participation are postponed. The model is fitted using data collected by the Survey of Health, Aging and Retirement in Europe (SHARE) in 14 European countries. The results show that on average across these countries, the effect of health on labour force participation levels is small. This effect is slightly bigger in countries in which labour force participation levels and the share of the population receiving disability benefits are already high. Thus, the decline in physical health with age should not greatly limit the effectiveness of policies designed to encourage employment at older ages.
\end{abstract}

\section{Introduction}

In the context of population ageing, measures are being taken in many OECD countries to promote work at older ages. One such measure is raising the pensionable age, or the age at which workers can start collecting pension benefits.

\footnotetext{
* Michael Boissonneault (corresponding author), Netherlands Interdisciplinary Demographic Institute (NIDI-KNAW)/University of Groningen, The Netherlands

Address for correspondence: P.O. Box 11650, NL-2502 AR The Hague, The Netherlands

Email: boissonneault@ nidi.nl.

Joop de Beer, Netherlands Interdisciplinary Demographic Institute (NIDI-KNAW)/University of Groningen, The Netherlands
} 
Examples of countries that have increased the pensionable age include the United States, the Netherlands, the United Kingdom, Italy, and France (OECD, 2015).

Concerns have been raised about whether people will remain healthy enough to be able to continue to participate in the labour market as they grow older. The implicit assumption of linking changes in the pensionable age to changes in life expectancy is that the ability to work changes along with life expectancy. However, shifts in healthy life expectancy are arguably more closely related to changes in the ability to work than life expectancy as such. So far, the question of whether longer life is accompanied by more years in good health has not been fully answered. While the prevalence of severe disability seems to be declining over time, less severe forms of disability are becoming more common (Klijs et al. 2010; Lefrancois et al. 2013; Cambois et al. 2008). Trends in chronic conditions suggest that morbidity is expanding (Chatterij et al. 2015; Crimmins and Beltran-Sanchez 2011). Other measures of health have uncovered contradictory trends in different countries (Tsimbos and Verropoulou 2016).

People often retire before reaching pensionable age, and secure income via other governmental programmes. Retiring prior to reaching pensionable age is associated with poorer health. This association is weaker among people who collect early retirement benefits or unemployment benefits (Bazzoli 1985; Alavinia and Burdorf 2008; Robroek et al. 2013) but stronger among people who collect disability benefits (Boersch-Supan and Roth 2010; Karpansalo et al. 2004; Robroek et al. 2013). If healthy life expectancy stays constant over time and people do not become eligible for pension benefits until they reach a higher age, we can assume that more people will use these routes to early retirement. This dynamic could put more pressure on these programmes, thereby undermining the efficiency of a higher pensionable age. But how big is this problem likely to be?

In the present paper, we aim to quantify the potential impact on labour force participation levels if the health of the population fails to improve when the pensionable age is raised. We examine the European context, where important changes in retirement dispositions are to be expected. The contribution of our paper is twofold. First, we provide tools that help in conceptualising and modelling the link between changes in legislation around retirement, work, and health at older ages. Second, we provide evidence that sheds light on the debate about whether people will be healthy enough to be able to continue to participate in the labour force at older ages.

The paper is organised as follows. First, we provide a framework that establishes the conditions for higher participation in the context of a higher retirement age. Then, in the methods section, we give an overview of the data and variables used, we introduce the model, and we show how the simulation is performed. In the results section, we illustrate the fit of the model. Next, we present the results of the simulation for an average European country, first in the form of working life expectancy, then in the form of characteristics-based ages. In the last part of the results section, we test the sensitivity of the results by running the simulation on 
two groups of countries that differ concerning work and health at older ages. In the last section, we discuss the findings and the limitations of the study.

\section{Framework}

The increase in the age at which individuals become eligible to receive pension benefits is expected to have a positive effect on labour force participation levels at older ages. To our knowledge, however, it has never before been clearly stated how much labour force participation levels are expected to increase as a result of raising the normal retirement age. Furthermore, we know of no existing framework that has clarified through which mechanisms changes in the pensionable age will lead to higher labour market participation levels. In this section, we propose a framework that sheds light on these two issues.

Our framework builds on the characteristics approach to the measurement of population ageing developed by Sanderson and Scherbov (2013). The application of this approach has shown that the pace at which the average individual ages varies across different populations and subpopulations. Because chronological age is always computed the same way (i.e., using time from birth), it does not capture such differences. The characteristics that are relevant for defining how old a person is can be used alongside age to compare how people age across subpopulations. For example, a study conducted in the United States used the characteristics approach to compare the ageing rates of different subpopulations based on grip strength. The results showed that, on average, more educated people of a given chronological age had the same grip strength as less educated people with a younger chronological age. The authors therefore concluded that as measured by grip strength, more educated people age at a slower pace than less educated people (Sanderson and Scherbov 2014).

We consider here a hypothetical country with a normal retirement age of 65 years old. The characteristic "being eligible for pension benefits" is bound to age 65. Let us further assume that, in the same country, legislation is passed that postpones eligibility by two years of age. The individuals affected by the change in legislation will have the characteristics "being eligible for pension benefits" at the chronological age of 67 instead of 65 . In both cases, however, the characteristicsbased ages of these people are the same as measured by eligibility for pension benefits.

Eligibility for pension benefits does not always equate to retirement, as people often retire before or after that age. In the present paper, we are interested in people's behaviour as measured by their participation in the labour force. We will therefore concentrate on the characteristic "being out of the labour force because of retirement". We will assume that a change in legislation that postpones by $n$ years the age at which an individual becomes eligible for pension benefits is intended to encourage an equivalent postponement of retirement. In other words, we assume a change of two years in the characteristic "being eligible for pension benefits" to 
mean an expected change of two years in the characteristic "being out of the labour force because of retirement", regardless of the age at which the change takes place.

Whether this expectation will materialise depends on the change in the schedule of all of the characteristics that together determine the timing of retirement. This set of characteristics includes, for example, the social norms regarding retirement and financial preparedness. The discrepancy between the expected change in retirement timing and the actual change will depend on two things: the size of the impact of each characteristic of the set on retirement timing; and the amount of change that takes place in this characteristic's schedule.

In the present paper, we investigate the specific impact of one of those characteristics; namely, physical health. Cross-sectional studies have consistently shown that there is an association between being in poor physical health and leaving the labour force before reaching the statutory retirement age. For example, conditions like stroke, diabetes, heart disease, and arthritis (Alavinia and Burdorf 2008; Smith et al. 2013; Kalwij and Vermeulen 2008); a lack of physical activity (Alavinia and Burdorf 2008); musculoskeletal problems (Alavinia and Burdorf 2008; Smith et al. 2013); and lower grip strength (Boersch-Supan and Roth 2010; Kalwij and Vermeulen 2008) are all factors associated with being out of the labour force prior to reaching the statutory retirement age. These associations hold when studied from a cross-sectional (Van Rijn et al. 2014) as well as from a longitudinal perspective (Van der Noordt et al. 2014).

Out of all of the characteristics that could hinder an increase in the labour market participation rates of older people, we consider the characteristic physical health to be of particular importance. While it may be possible to intervene to support some personal characteristics that pertain to the capacity of an older person to perform work, like motivation or skills; there is little that can be done to reverse a decline in physical health with age (Ilmarinen 2001). Furthermore, while changes in legislation may be able to influence characteristics like norms or financial preparedness, they have no or little impact on physical health.

Another important characteristic that influences work ability is mental health. The relationship between retirement and mental health is complex. While mental health has been found to have an impact on retirement (Olesen 2011), the opposite causality has also been found (Van der Heide 2013). Thus, age-related changes in mental health can be misleading (Riffe et al. 2015). By contrast, physical health can be more easily considered as a function of age, as there is no consistent evidence that retirement affects this dimension of health (Johnston and Lee 2009). For this reason, we focus on physical health, although the method used to measure physical must be chosen with care (Bound and Waidman 2007).

In the present paper, we propose a simulation in which we simulate a change in legislation that postpones eligibility for pension benefits by $n$ years. We thereby assume that except for physical health, all of the characteristics that determine timing to retirement are also postponed. We then provide a measure of the discrepancy between the expected $n$ value and the actual $n$ value that originates 
from delaying the schedule of all characteristics that predict timing to retirement except physical health.

\section{Methods}

\subsection{Data Source}

We use data from wave 2 (2006-2007) of The Survey of Health, Ageing and Retirement in Europe (SHARE) (Börsch-Supan et al. 2008; Börsch-Supan et al. 2013; Börsch-Supan 2016) ${ }^{1}$. Although SHARE offers data at more points in time, wave 2 is the wave that best suits our needs in terms of measures of physical health. Furthermore, using data from this period allows us to avoid the negative impact that the Great Recession had on labour market participation at older ages in many countries. The countries that participated in wave 2 are Austria, Germany, Sweden, the Netherlands, Spain, Israel, Italy, France, Denmark, Greece, Switzerland, Belgium, the Czech Republic, Poland, and Ireland. We dropped observations collected in Israel to focus on Europe only. We further limit the observations we use to those in which the respondents were aged 50-64 at the time of the interview. The lower age limit is imposed by the survey. The upper age limit was chosen because the estimates become increasingly erratic at higher ages as the number of people who remain active in the labour market declines. The number of observations for those countries at these ages is 17,983. Figure 1 breaks them down by country.

\subsection{The variables}

\subsubsection{The health variable}

The health variable is a composite measure in which we take the average of the standardised score obtained in three tests of physical health: grip strength, lung strength, and chair stand. Although SHARE offers more measures of health, we have chosen to limit ourselves to these three as they are the only measures available that are objective and measured on a continuous scale. The objective property allows us to avoid any justification bias (Lindeboom and Kerkhofs 2009), while

\footnotetext{
1 The SHARE data collection has been primarily funded by the European Commission through FP5 (QLK6-CT-2001-00360), FP6 (SHARE-I3: RII-CT-2006-062193, COMPARE: CIT5-CT-2005028857, SHARELIFE: CIT4-CT-2006-028812) and FP7 (SHARE-PREP: N²11909, SHARE-LEAP: $\mathrm{N}^{\circ}$ 227822, SHARE M4: $\mathrm{N}^{\circ}$ 261982). Additional funding from the German Ministry of Education and Research, the U.S. National Institute on Aging (U01_AG09740-13S2, P01_AG005842, P01_AG08291, P30_AG12815, R21_AG025169, Y1-AG-4553-01, IAG_BSR06-11, OGHA_04-064), and from various national funding sources is gratefully acknowledged (see www.share-project.org).
} 


\section{Figure 1:}

Number of observations included in the dataset, by country

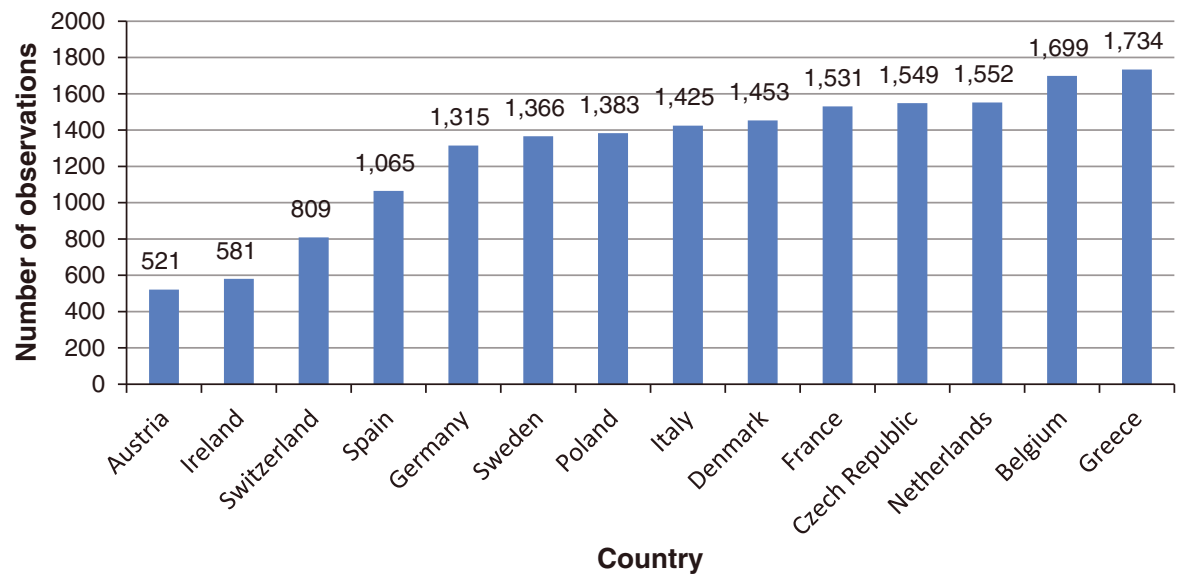

the continuous property enables us to make a more precise assessment of the impact of health on labour force participation (more on this below). The three measures are all part of SHARE's module on objective measures of physical health. A fourth measure, walking speed, is not used here as it is only collected among people aged 75 and older.

Grip strength measures upper body strength, and is also an indicator of general physical vitality. It is assessed using a Smedley spring-type dynamometer, and is given in kilograms. Grip strength has been shown to predict incapacity, hospital stays, death, and decline in cognitive health. Good reviews of the literature on the link between grip strength and different health outcomes can be found in Bohannon (2008) and Sanderson and Scherbov (2014).

The lung test is performed using a Mini-Wright Peak Flow Meter. The meter measures the maximum strength with which the respondent expires air out of his or her lungs. The result is given in litres per minute. This test is especially useful in detecting respiratory problems such as asthma and emphysema. It can predict death (Cook et al. 1991) and the decline in cognitive capacities (Albert et al. 1995), and is linked to other measures of physical health (Seeman et al. 1994).

The chair stand test measures lower body strength, and is also an indicator of general physical vitality. Some variants of this test exist. We use the variant where the participant is asked to sit on a chair with his or her arms crossed and to get up and sit down again five times as quickly as possible. The result of the test is given in seconds. This test has been shown to predict mortality (Cooper 2010), and constitutes a good proxy of general health (Jones et al. 2000; Rozanska-Kirschke et al. 2006). 


\subsubsection{Labour force participation}

The SHARE participants were asked about their labour force status at the moment of the interview. SHARE breaks down the answers into six categories: retired, working, unemployed, permanently disabled, homemaker, and other. We considered the people who were classified as working or unemployed to be active on the labour market, and assigned them the value one. Conversely, we considered the people who were classified as belonging to any of the other categories to be inactive, and assigned them the value zero.

\subsubsection{Imputation}

Some observations did not have a valid value for each variable of health or for the variable of labour force participation. Furthermore, the values that were less than three seconds for the chair rise were reconverted into missing, as we judged them to be very unlikely. This cut-off is based on another survey that contains results for the same test ${ }^{2}$. The numbers of missing values are as follows: 1183 observations concerning grip strength, 1773 observations concerning lung strength, 3379 observations concerning the chair stand, and 469 observations concerning labour force participation.

The missing values for health are mainly attributable to the respondent being unable to perform the necessary test, often because of a temporary or a long-lasting injury or disability. Accordingly, having a missing value is significantly associated with worse self-assessed health (regression models controlling for age and sex; coef: -.5400 (grip); -.4449 (peak); .6048 (chair); all significant at the 0.01 level). Ignoring those values would likely underestimate the impact of physical health on work.

We used multiple imputation in order to replace the missings with imputed values (Little and Rubin 2002). We performed a sequential imputation using a logistic regression on labour force status and a linear regression on grip strength, lung strength, and chair stand. The predictors were self-assessed health, country, gender, and age. The analyses were produced based on the average of 25 imputations. The command mi impute of the programme Stata version 12 was used to produce the imputation (Stata Corp 2011).

\subsubsection{Standardization}

Our analyses are based in part on the density function of the composite measure of physical health. We assume that each of the three measures of physical health are normally distributed. From the outset, the distributions of the grip and lung

2 The English Longitudinal Survey on Ageing did not contain any value below three concerning this same measurement. 
Table 1:

Summary statistics for the three measures of health, men

\begin{tabular}{lccc}
\hline & Grip strength & Lung strength & Chair stand (log) \\
\hline Mean & 47.9 & 466.4 & 2.7 \\
Median & 48.0 & 470.0 & 2.7 \\
Minimum & 1.0 & 31.0 & 0.4 \\
Maximum & 84.0 & 880.0 & 3.9 \\
Skewness & -0.3 & -0.2 & -0.9 \\
\hline
\end{tabular}

Table 2:

Summary statistics for the three measures of health, women

\begin{tabular}{lccc}
\hline & Grip strength & Lung strength & Chair stand (log) \\
\hline Mean & 29.4 & 319.7 & 2.6 \\
Median & 30.0 & 320.0 & 2.7 \\
Minimum & 0.0 & 32.0 & 0.5 \\
Maximum & 75.0 & 850.0 & 3.9 \\
Skewness & 0.0 & -0.1 & -1.0 \\
\hline
\end{tabular}

strength outcomes were fairly close to a normal distribution for each sex. The chair stand outcomes were skewed to the right. We reconverted this measure's values into their natural logarithms. Tables 1 and 2 present some summary statistics on the distribution of each variable of health for men and women, respectively.

Since the value of each measure of health may not have the same meaning between the sexes and across countries, we reconverted each measure according to the standard deviation to which it belonged. The standard deviations were computed by sex and country. For each measure, we created 60 categories with a 0.1 standard deviation width going from three standard deviations below the median up to three standard deviations above the median. The values below and above those marks were considered to be extreme outliers, and the observations to which they belonged were dropped. The analyses were run on a total of 17,507 observations. As the results of the Pearson test displayed in Table 3 show, each measure of health is relatively independent of the other two. We therefore assume that the composite measure covers a fairly broad spectrum of physical health. 
Table 3:

Correlation matrix between the measures of physical health grip strength, lung strength, and chair stand

\begin{tabular}{lcc}
\hline & Grip strength & Lung strength \\
\hline Grip Strength & & \\
Lung Strength & 0.2040 & \\
Chair Stand & 0.3438 & 0.2427 \\
\hline
\end{tabular}

\subsection{The model}

The goal of the model is to isolate the specific influence of physical health from the other factors that influence retirement timing. This will allow us to simulate a postponement of all the characteristics that are relevant to retirement timing, except for physical health. The model rests on three building blocks: (1) participation as a function of age, (2) health as a function of age, and (3) participation as a function of health. The model is fully parameterised, which allows us to obtain more consistent estimates. Here we give a formal description of the model.

(1) Participation as a function of age. Age captures much of the variation in participation at older ages. It is a good proxy for different underlying factors that determine retirement timing, such as financial preparedness, norms, and health. We model change in labour force participation according to age following the logistic function

$$
L_{x}=c_{l}+\frac{a_{l} e^{b_{l}\left(x-m_{l}\right)}}{1+e^{b_{l}\left(x-m_{l}\right)}}
$$

where $L_{x}=$ the proportion of people participating in the labour market at age $x, b$ determines the strength of the age-related change in participation, $m$ is the age at which the slope is the steepest (i.e., the modal age of exits from the labour market), $c$ is the lower boundary (i.e., the minimum proportion of people active) and $c+a$ is the upper boundary (i.e., the maximum proportion of people active). The subscript $l$ refers to labour force participation. In estimating the parameters we imposed the constraint that $c$ could not go below zero, as negative participation is impossible.

(2) Health as a function of age. The tendency for health to decline with age is the main reason why the ability of people to postpone retirement to higher ages has been questioned. The normally distributed variable of health is modelled based on its mean value and standard deviation. We modelled change in mean health according to age based on a logistic function, supposing that mean health varies between an upper and a lower boundary as we move along the $x$ axis representing age

$$
\mu_{x}=c_{h}+\frac{a_{h} e^{b_{h}\left(x-m_{h}\right)}}{1+e^{b_{h}\left(x-m_{h}\right)}}
$$


where $\mu_{x}=$ mean health at age $x, b$ determines the strength of age-related changes in mean health, $m$ is the age at which the slope is the steepest, $c$ is the lower boundary (i.e., the minimum mean health) and $c+a$ is the upper boundary (i.e., the maximum mean health). The subscript $h$ refers to health status.

We consider the health of the active population on the one hand, and the health of the whole population on the other. For each specification of the model, the health of the active population was found to be significantly better than the health of the non-active population (controlling for age and sex). Due to some random fluctuations, the curves of the age-specific mean values of physical health for the active population and for the whole population sometimes crossed. In order to obtain a realistic model, we impose two constraints. For both populations we set $c$ at zero, based on the assumption that both curves approach zero as the age gets higher. We then impose the assumption that $a$ is at least as high for the active population as for the whole population.

The health function of age is further defined in terms of the age-specific standard deviations. The variation in the observed standard deviations according to age do not show any significant slope. As there is also no theoretical reason to believe that the standard variation should vary according to age, we model the standard variation based on the average standard deviation observed between ages 50 and 64 for both sexes.

(3) Participation as a function of health. The variation in participation according to health is found based on the age-participation functions as well as on the agehealth function described above. Based on the age-specific mean health and standard deviations, we find for each age the health density of the whole population. Using the same parameters, we find the health density of the active population, and we weight it according to the age-participation function described by Equation (1). The health-specific levels of participation are found by dividing the function describing the health of the active population weighted by the proportion participating in the labour market by the function describing the health of the whole population.

More formally, the health of the whole population is defined in terms of the density function

$$
W_{h, x}=\frac{1}{\sigma_{w, x} \sqrt{2 \pi}} e^{-\frac{1}{2}\left(\frac{h-\mu_{w, x}}{\sigma_{w, x}}\right)^{2}}
$$

where $W_{h, x}=$ the share of the whole population with health status $h$ at age $x, \mu_{w, x}$ is the mean health of the whole population at age $x$ as provided by Equation (2), $\sigma_{w, x}$ is the standard deviation of the health measure of the whole population and $h$ is a health value of infinitesimal width.

The health of the active population is defined in terms of the product of the agespecific level of participation and of the density function

$$
A_{h, x}=L_{x}\left(\frac{1}{\sigma_{a} \sqrt{2 \pi}} e^{-\frac{1}{2}\left(\frac{h-\mu_{a, x}}{\sigma_{a}}\right)^{2}}\right)
$$


where $A_{h, x}=$ the share of the active population with health status $h$ at age $x, L_{x}$ is the participation level at age $x, \mu_{a, x}$ is the mean health of the active population at age $x$ as provided by Equation (2), $\sigma_{a, x}$ is the standard deviation of the health measure for the active population and $h$ is a health value of infinitesimal width.

We divide the proportion of people who are active on the labour market inside of the density function of the active population by the density function one of the whole population. This provides us with health- and age-specific labour force participation rates

$$
\frac{A_{h, x}}{W_{h, x}}=l_{h, x}
$$

where $l_{h, x}=$ the level of participation at health $h$ and age $x$.

\subsection{The simulation}

The simulation consists of applying the set of health-specific levels of participation described by Equation (5) to the population who are six years older. We base this figure on Eurostat's projections of increases in life expectancy at age 65 up to 2057 (Eurostat high variant scenario; Eurostat 2016b), as many countries have decided to synchronise their changes in the pensionable age with changes in life expectancy (OECD 2011).

The simulation can be described as a twostep procedure. First, the product of the postponed health-specific levels of participation and of the health density of the whole population is found

$$
l_{h, x+n, t} W_{h, x, t}=A_{h, x, t+T}
$$

where $A_{h, x, t+T}=$ the density for the population who are active in the labour market with health $h$ and age $x$, supposing a postponement in all of the characteristics inherent to retirement timing except for physical health. Then, by summing up the values of $A$ over all values of

$$
h \sum_{h} A_{h, x, t+T}=l_{x+n, t+T}
$$

we obtain a set of age-specific participation rates, where $l_{x+n, t+T}=$ the age-specific participation rate based on the assumption of a postponement of all of the factors that allow people to work longer, except physical health.

\section{Results}

The results are presented in three parts. First, we present the outcomes for men and women, pooling the data from all of the countries included in the dataset. We also demonstrate the fit of the model and illustrate how we simulated a postponement 
of retirement while keeping physical health constant. Second, using working life expectancy, we present for the same sets of observations the size of the impact of declining physical health on the postponement of retirement. Third, we assess the sensitivity of the results by comparing them between two groups of countries.

\subsection{Fitting the model}

Figure 2 presents for men and women the fitted and the observed values of labour force participation by year of age (Panel 1), mean health by year of age (Panel 2) and the standard deviation by year of age (Panel 3). The fitted values give the $L, \mu$ and $\sigma$, parameters, respectively.

The $\mu$ and $\sigma$ values represented by the blue line (whole) in Panel 2 and in Panel 3 allow us to obtain health densities for the whole population for each year of age (Equation 3). The health density of men aged $55, W_{x, 55}$, is represented in blue in the top left graph of Figure 3. The $\mu$ and $\sigma$ values represented by the red line (active) in Panels 2 and 3 of Figure 2 allow us to obtain health densities for the active population (Equation 4). These densities are multiplied by the proportion of people of the same age who are active on the labour market as described in Panel 1 of Figure 2. The resulting proportion is represented by the red bell-shaped surface in the top-left graph of Figure $3\left(A_{x, 55}\right)$.

Dividing the red bell-shaped surface with the blue bell-shaped line of the top-left graph of Figure 3 (Equation 5) provides us with the top-right graph in the same figure. The curve represents the health-specific participation rates $\left(l_{h, 55}\right)$.

The blue bell-shaped line in the bottom-left graph represents the health density of men aged 61. These men are assumed to have the same labour force participation levels as people aged 55 after postponement. However, the health of the 61-yearold men is worse than that of the 55-year-old men, as represented by the lower $\mu$ value (age $55=31.5$; age $61=29.4$ ). We multiply this health function by the health-specific participation levels of people aged 55 (Equation 6), as represented in the top-right graph $\left(l_{h, 55}\right)$. This provides us with the surface inside the bell curve represented in red; i.e., with the proportion of people working at age 61 supposing a six-year postponement of all of the factors that determine labour force participation except physical health (Equation 7). As a result of the limiting effect of declining physical health, the surface in red in the bottom-left graph is slightly smaller than the surface in red in the top-left graph.

Figure 4 illustrates the same process taking place between age 60 (baseline) and age 66 (postponement). Here we see that both the health and the participation levels decline with age. Figure 5 illustrate the resulting levels of participation for all years of age and compares them with the levels that would have been obtained if the decline in physical health had been postponed along with the rest of the characteristics that determine retirement timing. 
Figure 2:

Estimated and observed values, proportion participating in the labour market, mean health, and standard deviation of health, men and women

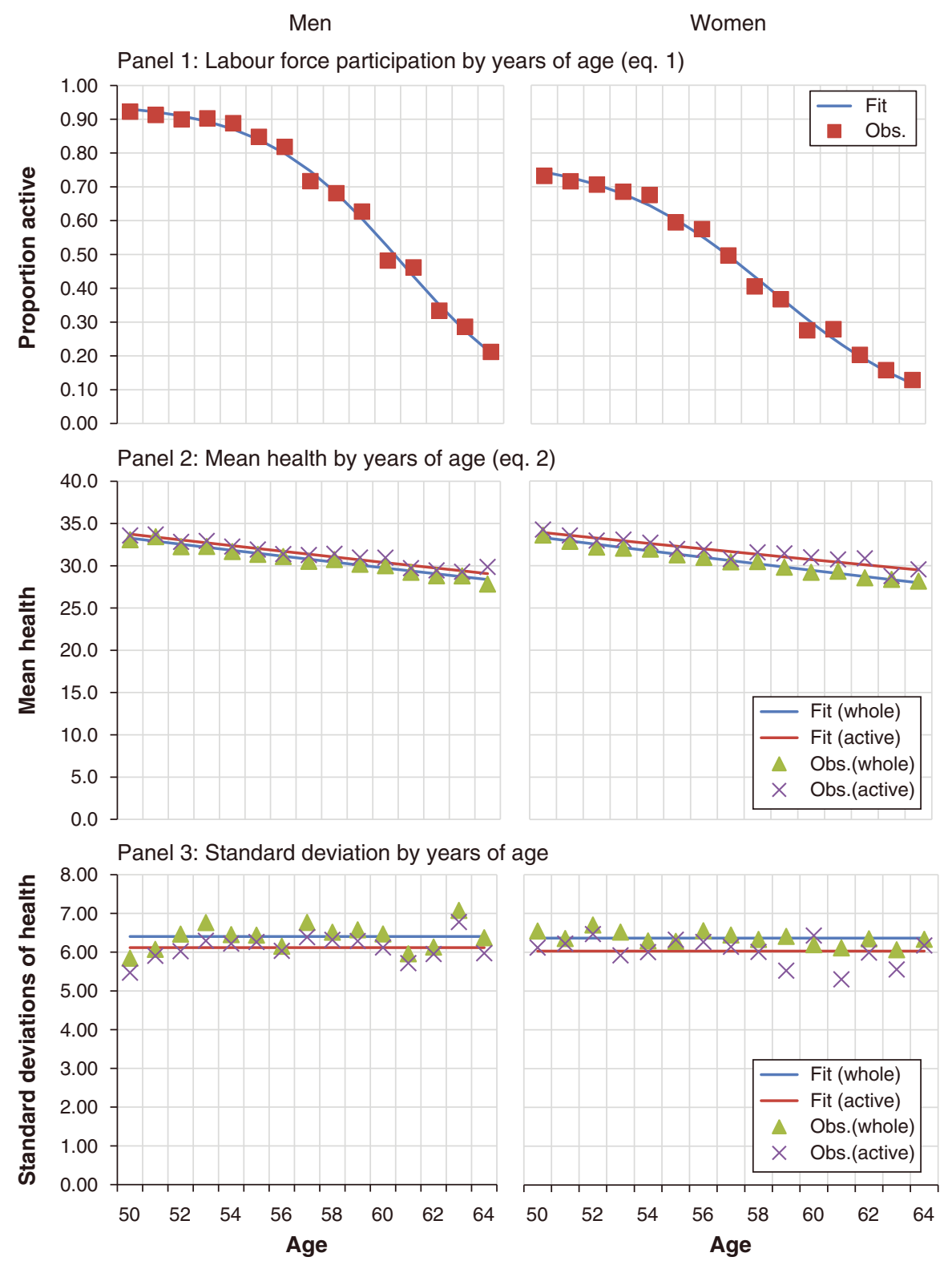


Figure 3:

Illustration of the simulation of a postponement of retirement keeping physical health constant, men, aged 55 to 61
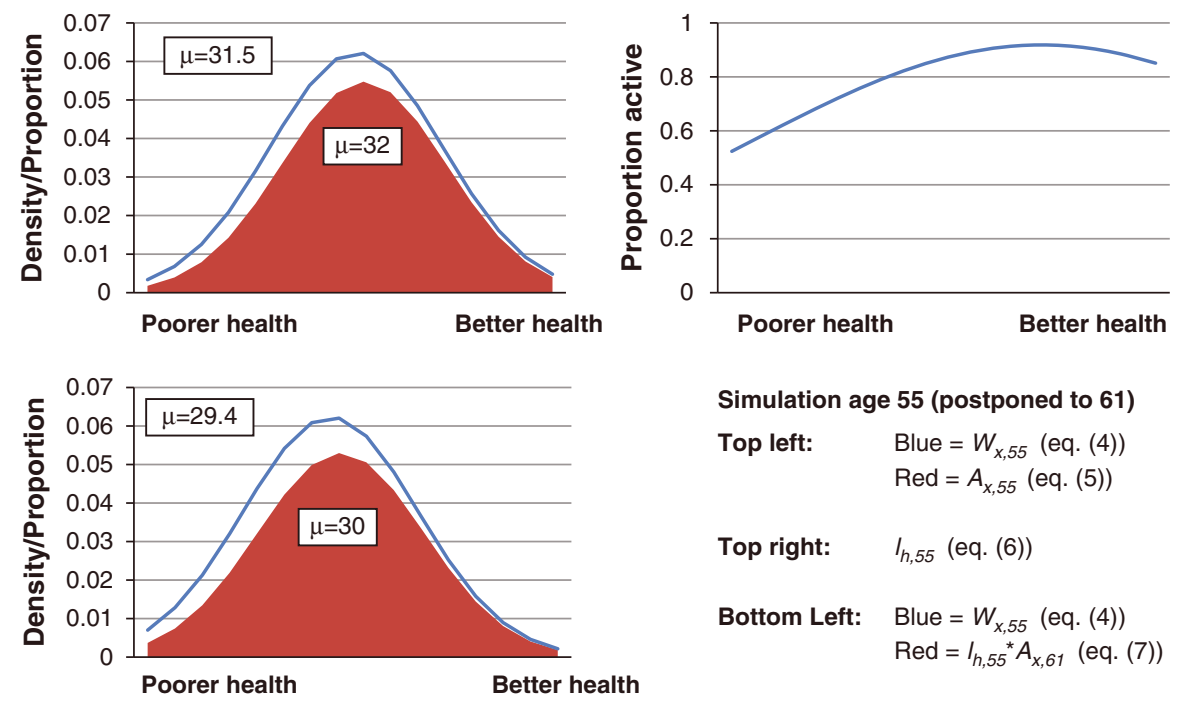

Simulation age 55 (postponed to 61)

Top left:

Blue $=W_{x, 55}$ (eq. (4))

Red $=A_{x, 55}$ (eq. (5))

Top right: $\quad I_{h, 55}$ (eq. (6))

Bottom Left: Blue $=W_{x, 55}$ (eq. (4))

Red $=I_{h, 55}{ }^{*} A_{x, 61}$ (eq. (7))

Figure 4:

Illustration of the simulation of a postponement of retirement keeping physical health constant, men, aged 60 to 66
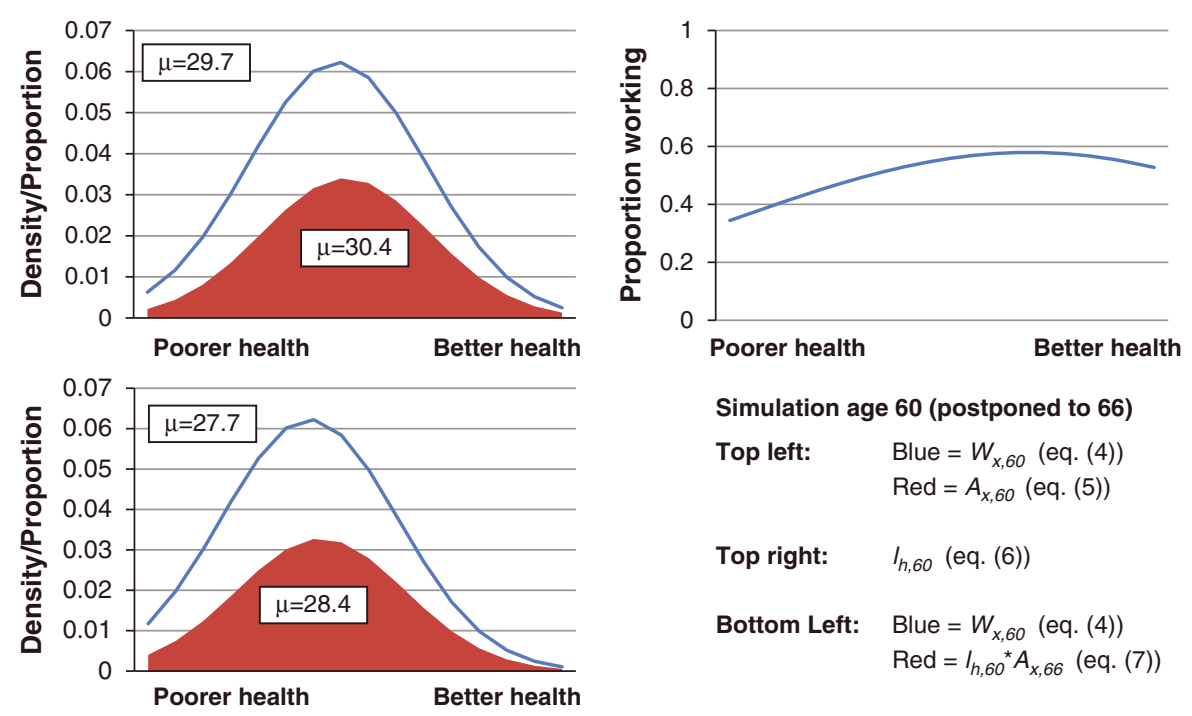

Simulation age 60 (postponed to 66 )

Top left: $\quad$ Blue $=W_{x, 60}$ (eq. (4))

$\mathrm{Red}=A_{x, 60}$ (eq. (5))

Top right: $\quad I_{h, 60}$ (eq. (6))

Bottom Left: $\quad$ Blue $=W_{x, 60}$ (eq. (4))

$\operatorname{Red}=I_{h, 60}{ }^{*} A_{x, 66}$ (eq. (7)) 


\section{Figure 5:}

Proportion active in the labour market by year of age, with and without the limiting effect of physical health on postponement

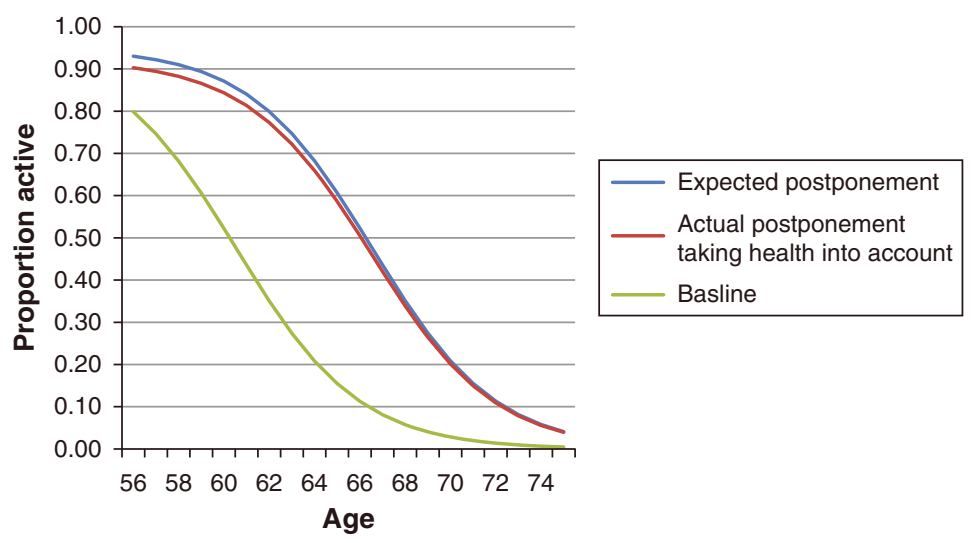

\subsection{Working life expectancy}

As a way to present the results, we computed abridged working life expectancy for each sex, pooling all observations from the 14 countries. The results represent the situation of an average European country. Here, the working life expectancy is just the area under the participation curve, as defined by Equation (7). It is calculated on 20 years of age, and conditionally on being active at baseline (i.e., the area under the curve is divided by participation at baseline).

The working life expectancy was first calculated between age 50 and age 70 , without supposing any change in characteristics. The results of this computation are represented in Figure 6 by the full bars, which reach 10.74 years for men and 9.28 years for women. The postponement of the eligibility for retirement benefits, with a corresponding postponement in the whole set of characteristics inherent to retirement timing including physical health would mean that people aged 56-76 would, at baseline, have the same working life expectancy as people aged 50-70. The right part of the bars shows the discrepancy introduced by the failure to postpone the decline in physical health, while all of the other factors are postponed. The discrepancy is quite small in each case; reaching 0.36 years for men and 0.55 for women.

Another way to look at the same results is by using the characteristics-based age. Here, we use the remaining working life expectancy as a characteristic to assess the size of the discrepancy introduced by postponing all of the factors inherent in labour force participation except health. The results are presented in Table 4. Assuming a six-year postponement, people aged 56 are expected to have the same remaining working life expectancy as people aged 50 if all of the relevant factors are postponed. 
Figure 6:

Working life expectancy ages 56-76, with and without the limiting effect of physical health on postponement, men and women

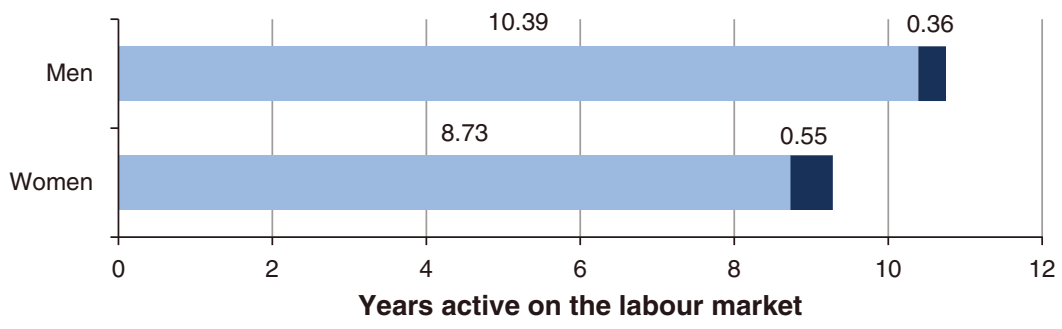

Table 4:

Age at which the working life expectancy is the same as the reference age, assuming a postponement of all of the factors except the decline in physical health, men and women

\begin{tabular}{clc}
\hline & \multicolumn{2}{l}{$\begin{array}{l}\text { Age at which the working life } \\
\text { expectancy is the same as the } \\
\text { reference age }\end{array}$} \\
\cline { 2 - 3 } Reference age & Men & Women \\
\hline 56 & 55.62 & 55.42 \\
\hline
\end{tabular}

The failure to postpone the decline in physical health brings this figure down to 55.62 for men and to 55.42 for women.

\subsection{Sensitivity analysis}

The results presented above give us an idea of the impact of a constant age profile of physical health when the rest of the factors predicting retirement are postponed in an average European country. Here, we assess whether this average could hide big discrepancies between countries. In order to obtain more stable estimates, we produced results for two groups of countries rather than for single countries.

The groups are built so that they diverge from each other in terms of the impact of health on the postponement of retirement. The first group is comprised of countries that have higher levels of labour force participation at older ages and higher shares of the population aged 50-65 receiving disability benefits: namely, Sweden, Denmark, the Netherlands, Ireland, the Czech Republic, and Spain. The second group is comprised of countries that have lower levels of participation and lower shares of 
Figure 7:

Working life expectancy ages 56-76, with and without the limiting effect of physical health on postponement, men and women, high vs. low impact countries

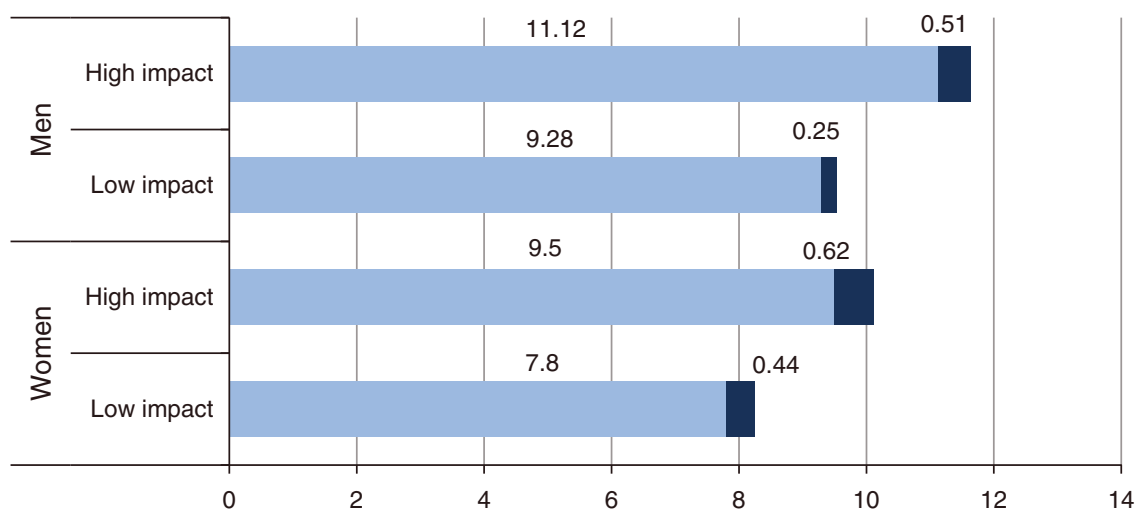

the population aged 50-65 receiving disability benefits: namely, France, Greece, Austria, Belgium, and Italy. Levels of participation at older ages are calculated by Eurostat for the year 2007 (Eurostat 2016a). The proportions of the population receiving disability benefits are calculated based on auto-declaration, and are found in Boersch-Supan (2010). The proportions of the population who are active at older ages and the proportions of the population receiving disability benefits are summarised in the appendix.

Our a priori assumption is that the impact of physical health on the postponement of retirement will be bigger in the first group, because the people in this group tend to still be working at higher ages, and older people tend to be in poorer physical health. Furthermore, we expect the higher share of the population receiving disability benefits to translate into a bigger impact of health on labour force participation. We call the first group the high-impact countries, and the second group the low-impact countries.

The results in Figure 7 confirm our expectation. In the high-impact countries, the number of years men are expected to spend in the labour market between ages 56 and 76 is 11.63 . The actual figure is 11.12 ; a difference of 0.51 years. In the lowimpact countries, men are expected to spend 9.48 years in the labour market between ages 56 and 76 with the postponement of all characteristics. When the limiting effect of physical health is taken into account, the figure is 9.28; a difference of 0.25 years.

The discrepancy between the high- and the low-impact countries is smaller among women. The number of years women are expected to spend in the labour market between ages 56 and 76 assuming a postponement is 10.13 in the highimpact countries. The actual value after taking the limiting effect of physical health into account is 9.50; a difference of 0.62 years. In the low-impact countries, working 
Table 5:

Age at which the working life expectancy is the same as the reference age, supposing a postponement of all factors except physical health, men and women, high- vs. low-impact countries

\begin{tabular}{ccccc}
\hline \multicolumn{4}{c}{$\begin{array}{l}\text { Age at which the working life expectancy is the same as } \\
\text { the reference age }\end{array}$} \\
\cline { 2 - 5 } Reference age & Men high & Men low & Women high & Women low \\
\hline 56 & 55.47 & 55.74 & 55.33 & 55.55 \\
\hline
\end{tabular}

life expectancy is 8.24 years when the postponement of all factors is assumed. The actual figure is 7.80 ; a difference of 0.44 years.

The characteristic ages translate into the same results. In the high-impact countries, men aged 55.47 and women aged 55.33 have the same working life expectancy as their 50-year-old counterparts at baseline. In the low-impact countries, men aged 55.74 and women aged 55.55 have the same working life expectancy as their 50-year-old counterparts at baseline.

\section{Discussion}

In the present paper, we proposed a simulation of the impact of physical health on labour force participation when the age at retirement is postponed. The simulation was based on a framework in which we considered physical health as a distinct characteristic predicting retirement timing. In this framework, physical health was the only characteristic that was not postponed. The model - which is based on an age-function of labour force participation, as well as on changes in physical health according to age in the active population relative to the whole population allowed us to isolate the effect of physical health on participation. Physical health was measured objectively using standardised grip strength, lung strength, and chair stand tests. The estimates were based on data collected in 2006 and 2007 in 14 SHARE countries.

The results suggest that physical health had a limited effect on the postponement of retirement. We saw that the link between labour force participation and physical health varied little between people aged 56-76 years and people aged 50-70. More precisely, when we included in our analysis a postponement of all of the characteristics that are relevant to retirement timing except physical health, we found that relative to the younger group, the older group had a working life expectancy that was only 0.36 years shorter among men, and 0.55 years shorter among women. In other words, a man aged 55.62 and a woman aged 55.42 could expect to work as many years as their 50-year-old counterparts if all of 
the characteristics that predict retirement except for physical health are postponed six years. The results did show some sensitivity to country differences. This was especially true among men, for whom the impact of stagnating physical health doubled between the so-called low- and high-impact countries. However, the impact in these countries remained small, as the loss in terms of working life expectancy due to physical health hovered at around 0.5 years out of almost 12 years.

We attribute our finding that stagnating health had only a small effect on the postponement of retirement to the following mechanism. Although physical health has an important effect on labour force participation - as has been repeatedly shown in occupational health research - this effect is strong for only a relatively small number of people. Furthermore, although physical health declines considerably with age, it does not deteriorate so quickly that older people are unable to continue working at higher ages, as long as the postponement of retirement stays within reasonable boundaries. Our observation that the impact of physical health was greater in the countries in which higher shares of the population were participating in the labour market and receiving disability benefits confirms those findings.

These results echo the findings of some previous studies that examined the question of whether older people are physically and mentally able to work longer. Crimmins et al. (1999) and Reynolds and Crimmins (2010) found that the selfassessed ability to work has been rising in the American population aged 50-70 since the end of the 1980s. Milligan and Wise (2015) found for a sample of OECD countries and Rehkopf et al. (2016) found for the United States that the unused capacity to work at older ages was "substantial". Milligan and Wise reached that conclusion based on levels of labour force participation specific to mortality conditions over time, while Rehkopf et al. did so based on estimates of the link between labour force participation and a battery of health and socio-demographic variables.

These results, as well as the findings presented in this paper, all strongly suggest that health should not be a serious hurdle to higher labour force participation at older ages. The present paper expands the existing evidence in several ways. First, we documented the specific role of physical health. Moreover, our use of objective measures allowed us to avoid the justification bias, which has been shown to have the potential to bias upwards the effect of health on labour force participation. The three measurements (grip strength, lung strength, and chair stand) cover a broad spectrum of physical health characteristics. The model, which rests on a few parameters that are easy to estimate, is fairly simple and can be reproduced with data from SHARE's sister studies, like the Health and Retirement Study and the English Longitudinal Studies on Ageing.

However, the approach we used here has some limitations. We did not consider the role of mental health, which has also been shown to also have an important impact on early exits from the labour force. If the physical demands of work continue to decrease, studying the impact of mental health on the ability to continue working could become more relevant. The three measures of physical health that we used were the only ones available that met our criteria. Even though these measures 
have been shown to be fairly independent of each other, they do not necessarily cover all aspects of physical health. As a result, the impact of physical health on labour force participation could turn out to be somewhat larger than is estimated here, although we do not believe that the findings of a study that covered a wider range of physical health characteristics would be dramatically different. Finally, we did not investigate how the impact of health varies according to socioeconomic status. Given that levels of health differ considerably across subpopulations, and that the work done by people with lower socioeconomic status is often physically demanding, this question constitutes an important topic for future research.

\section{References}

Alavinia, S. and A. Burdorf 2008. Unemployment and retirement and ill-health: a crosssectional analysis across European countries. International Archives of Occupational and Environmental Health 82: 39-45.

Albert M. S., K. Jones, C. R. Savage, L. Berkman, T. Seeman, D. Blazer and D. W. Rowe 1995. Predictors of cognitive change in older persons: MacArthur studies of successful aging. Psychol Aging 10(4): 578-89.

Bazzoli, G. J. 1985. The Early Retirement Decision: New Empirical Evidence on the Influence of Health. The Journal of Human Resources 20(2): 214-234.

Bohannon, R. W. 2008. Hand-grip dynamometry predicts future outcomes in aging adults. J Geriatr Phys Ther 31: 3-10.

Börsch-Supan, A. and H. Roth 2010. Work disability and health over the life course. In The individual and the welfare state: Life histories in Europe. ed. Börsch-Supan, A. et al. Springer, Berlin. Forthcoming

Börsch-Supan, A. 2016. Survey of Health, Ageing and Retirement in Europe (SHARE) Wave 2. Release version: 5.0.0. SHARE-ERIC. Data set. DOI: 10.6103/SHARE.w2.500

Börsch-Supan, A., A. Brugiavini, H. Jürges, A. Kapteyn, J. Mackenbach, J. Siegrist and G. Weber 2008. First results from the Survey of Health, Ageing and Retirement in Europe (2004-2007). Starting the longitudinal dimension. Mannheim: Mannheim Research Institute for the Economics of Aging (MEA).

Börsch-Supan, A., M. Brandt, C. Hunkler, T. Kneip, J. Korbmacher, F. Malter, B. Schaan, S. Stuck, and S. Zuber 2013. Data Resource Profile: The Survey of Health, Ageing and Retirement in Europe (SHARE). International Journal of Epidemiology, DOI: 10.1093/ije/dyt088.

Bound, J. and T. Waidman 2007. Estimating the Health Effects of Retirement. University of Michigan Retirement Research Center. Working paper WP 2007-168, 36 p.

Cambois, E., A. Clavel, I. Romieu and J.-M. Robine 2008. Trends in disability-free life expectancy at age 65 in France: consistent and diverging patterns according to the underlying disability measure. European Journal Ageing 5: 287-298.

Chatterij, S., J. Byles, D. Cutler, T. Seeman and E. Verdes 2015. Health, functioning, and disability in older adults - present status and future implications. The lancet 385(9967): 563-575, 7-13 February 2015. 
Cook, N. R., D. A. Evans, P. A. Scherr, F. E. Speizer, J. O. Taylor and C. H. Hennekens 1991. Peak expiratory flow rate and 5-year mortality in an elderly population. American Journal of Epidemiology 133(8): 784-794.

Cooper, R. 2010. Objectively measured physical capability levels and mortality: systematic review and meta-analysis. BMJ 341: c4467.

Crimmins, E. M. and H. Beltran-Sanchez 2011. Mortality and morbidity trends: Is there compression of morbidity? The Journal of Gerontology Series B: Psychological Sciences and Social Sciences 66(1): 75-86.

Crimmins, E., S. L. Reynolds and Y. Saito 1999. Trends in health and work ability among the older working-age population. Journal of Gerontology: Social Sciences 54B(1).

Eurostat 2016a. Active population by age, sex and nationality. Eurostat database. http://ec.europa.eu/eurostat/data/database. Consulted on 22 November 2016.

Eurostat 2016b. Population projections. http://ec.europa.eu/eurostat/web/populationdemography-migration-projections/population-projections-data. Consulted on 22 November 2016.

Ilmarinen, J. E. 2001. Aging workers. Journal of Occupational and Environmental Medicine 58: 546 doi:10.1136/oem.58.8.546 E.

Jones C. J., Rikli R. E. and W. C. Beam 2000. A 30-s chair-stand test to measure lower body strength in community-residing older adults. J of Aging $\mathcal{E}$ Physical Activity 8: 85.

Johnston, D. W. and W. S. Lee 2009. Retiring to the good life? The short-term effects of retirement on health. Economic Letters 103: 8-11.

Kalwij, A. and F. Vermeulen 2008. Health and labour force participation of older people in Europe: What do objective health indicators add to the analysis? Health Economics 17(5): 619-638.

Karpansalo, M., P. Manninen, J. Kauhanen, T. A. Lakka and J. T. Salonen 2004. Perceived health as a predictor of early retirement. Scandinavian Journal of Work, Environment and Health 30(4): 287-292.

Klijs B., J. P. Mackenbach and A. E. Kunst 2010. Disability occurrence and proximity to death. Disability and Rehabilitation 32(21): 1733-1741.

Little, R. and D. B. Rubin 2002. Statistical analysis with missing data, second edition. Wiley

Lefrancois, G., S. Vezina, J. Keefe and J. Legare 2013. Trends and characteristics affecting disability amon older Canadians living in private households. Canadian Studies in Populations 40: 3-4.

Lindeboom, M. and M. Kerkhofs 2009. Health and work of the elderly: Subjective health measures, reporting errors and endogeneity in the relationship between health and work. Journal of Applied Econometrics 24: 1024-1046.

Milligan, K. and D. A. Wise 2015. Health and work at older ages: using mortality to assess the capacity to work across countries. Population Ageing 8: 27-50.

OECD 2011. "Linking Pensions to Life Expectancy", in Pensions at a Glance 2011: Retirement-income Systems in OECD and G20 Countries. OECD Publishing.

OECD 2015. Pensions at a Glance 2015: OECD and G20 indicators. OECD Publishing, Paris. DOI: http://dx.doi.org/10.1787/pension_glance-2015-en.

Olesen, S. C., P. Butterworth and B. Rodgers 2012. Social Psychiatry Psychiatric Epidemiology 47: 735. doi:10.1007/s00127-011-0375-7. 
Rehkopf, D. H., N. E. Adler and J. W. Rowe 2016. The impact of health and education on future labour force participation among individuals aged 55-74 in the United States of America: the MacArthur Foundation Research Network on an Aging Society, Ageing and Society, First View, published online: 11 April 2016.

Reynolds, S. L. and E. M. Crimmins 2010. Trends in the work ability among men and women in the older American population: 1997-2007. Eur J Ageing 7(4): 249-256. doi: 10.1007/s10433-010-0166-0.

Riffe, T., P. H. Chung, J. Spijker and J. MacInnes 2015. Time-to-death patterns in markers of age and dependency. MPIDR working paper WP 2015-003. July 2015.

Robroek S. J. W., M. Schuring, S. Croezen, M. Stattin and A. Burdorf 2013. Poor health, unhealthy behaviors, and unfavorable work characteristics influence pathways of exit from paid employment among older workers in Europe: a four year follow-up study. Scand J Work Environ Health 39(2): 125-133. doi:10.5271/sjweh.3319.

Różańska-Kirschke, A., P. Kocur, M. Wilk and P. Dylewicz 2006. The Fullerton Fitness Test as an index of fitness in the elderly. Medical Rehabilitation 10(2): 9-16.

Sanderson, W. C. and S. Scherbov 2013. The characteristics approach to the measurement of population aging. Population and Development Review 39: 673-685.

Sanderson, W. C. and S. Scherbov 2014. Measuring the speed of aging across population subgroups. PLoS ONE 9(5): e96289. doi:10.1371/journal.pone.0096289.

Seeman, T. E., P. A. Charpentier, L. F. Berkman, M. E. Tinetti, J. M. Guralnik, M. Albert, D. Blazer and J. W. Rowe 1994. Predicting changes in physical performance in a highfunctioning elderly cohort: MacArthur studies of successful aging. J Gerontol. 49(3): M97-M108.

Smith, P., C. Chen, C. Mustard, A. Bielecky and D. Beaton 2013. Examining the relationship between chronic conditions, multi-morbidity and labour market participation in Canada: 2000-2005. Ageing and Society Available on CJO 2013 doi:10.1017/S0144686X13000457.

StataCorp. 2011. Stata Statistical Software: Release 12. College Station, TX: StataCorp LP.

Van der Heide, I., R. M. Van Rijn, S. J. W. Robroek, A. Burdorf and K. I. Proper 2013. Is retirement good for your health? A systematic review of longitudinal studies. BMC Public Health 13: 1180.

Van der Noordt M., H. IJzelenberg, M. Droomers, et al. 2014. Health effects of employment: a systematic review of prospective studies Occup Environ Med 71: 730-736.

Van Rijn, R. M., S. J. W. Robroek, S. Brouwer and A. Burdorf 2014. Influence of poor health on exit from paid employment: a systematic review. Occupational and Environmental Medicine 71: 295-301.

Verropoulou, G. and C. Tsimbos 2016. Trends in disability in Europe using various indicators and SHARE data. Presented at the European Population Conference. 


\section{Appendix}

Figure A.1:

Percentage of the population aged 50-64 active on the labour market, by country

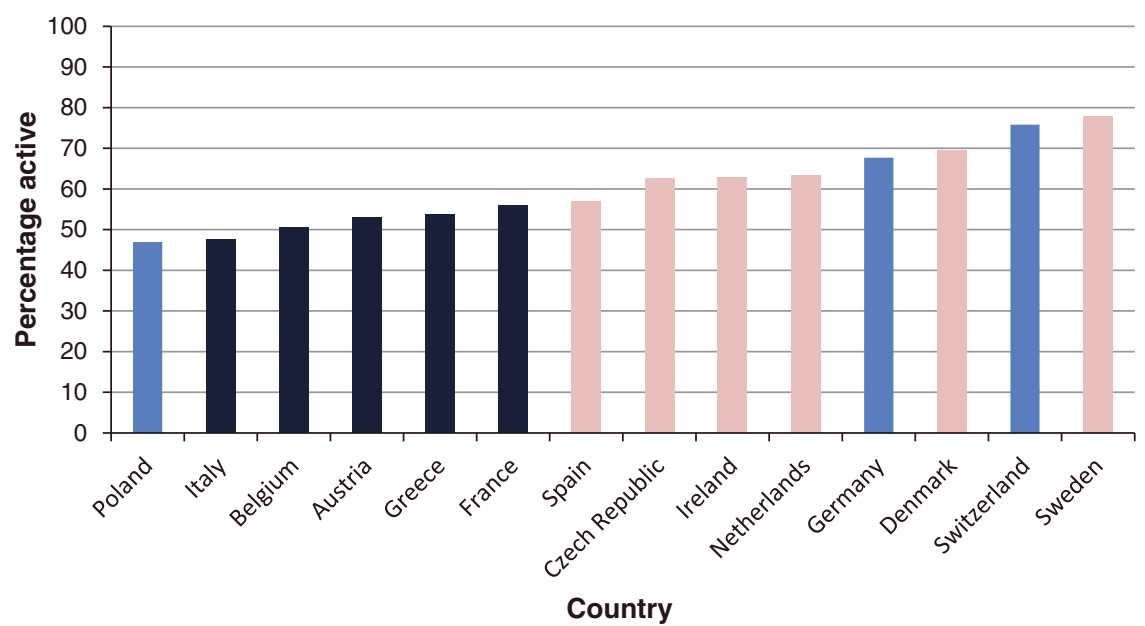

Figure A.2:

Percentage of the population aged 50-64 receiving disability benefits, by country

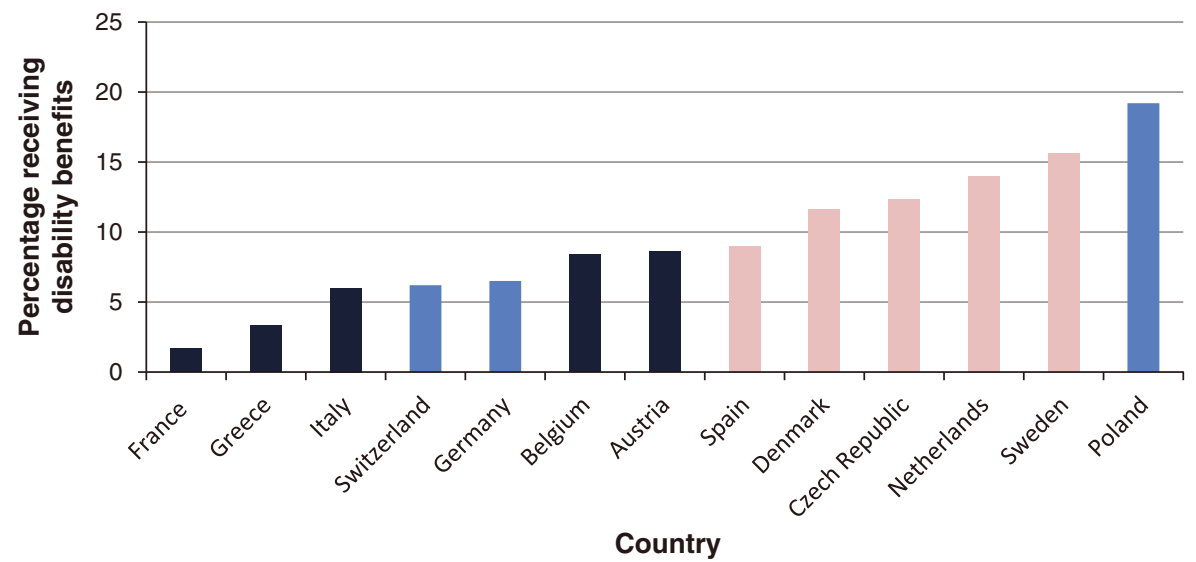


